\title{
An Efficient Model for Train-Track-Bridge-Coupled System under Seismic Excitation
}

\author{
Lizhong Jiang $\mathbb{D},{ }^{1}$ Tuo Zhou $\mathbb{D},{ }^{1}$ Xiang Liu $\mathbb{D}^{2},{ }^{2}$ Ping Xiang $\mathbb{D}^{1},{ }^{1}$ and Yuntai Zhang $\mathbb{D}^{1}$ \\ ${ }^{1}$ School of Civil Engineering, Central South University, Changsha 410075, China \\ ${ }^{2}$ School of Civil Engineering, Fujian University of Technology, Fuzhou 350118, China \\ Correspondence should be addressed to Tuo Zhou; zhoutuo1874@csu.edu.cn
}

Received 21 March 2021; Revised 6 August 2021; Accepted 17 August 2021; Published 31 August 2021

Academic Editor: Jie Yang

Copyright ( 2021 Lizhong Jiang et al. This is an open access article distributed under the Creative Commons Attribution License, which permits unrestricted use, distribution, and reproduction in any medium, provided the original work is properly cited.

When an earthquake occurs, due to the high operation speed of the train group, there is still a long distance from braking to stopping, so it needs a large number of bridge spans to calculate the integrated dynamic response, which leads to a large amount of calculation of the train-track-bridge (TTB) system under a seismic event. In order to reduce the amount of calculation, this paper proposed an efficient model called closed-loop model for simply supported railway bridge. The proposed model is realized by coupling the head and end of the rail-slab-bridge system through the utilization of pseudo-element. Simulation comparison of TTB response with and without seismic excitation between conventional TTB model and efficient model indicates that, under the premise of ensuring calculation accuracy, the efficient model shows the advantage of fewer degrees of freedom (DOF) of model and higher computational efficiency. For instance, under El Centro earthquake excitation, the time cost of proposed model is only $6 \%$ of conventional model. Meanwhile, six seismic events with different acceleration amplitudes are imposed on the efficient model, and the results of car-body acceleration, wheel-rail force, and wheel load reduction ratio are gathered and discussed; it can be concluded that, except Trinidad earthquake, for other earthquake samples investigated in this paper, with acceleration amplitude larger than $0.8 \mathrm{~g}$, the train operation is at the risk of derailment.

\section{Introduction}

With the popularity of high-speed railway (HSR) worldwide and the rapid development of HSR technology in recent decades, operation safety of HSR under extreme circumstances becomes an issue worthy of attention and research. As high-speed railway simply supported bridge (HSRSSB) has better geometry and stiffness irregularity, it is often used as the infrastructure of HSR line, as shown in Figure 1. In addition, the fact that China is located between the world's two major seismic belts, the Pacific Rim seismic belt and the Eurasian seismic belt, poses certain challenges to the earthquake resistance of high-speed railway bridges and the safety of train operation during earthquakes.

There are high-speed train derailments caused by earthquakes around the world, on October 23, 2004, a 6.8 magnitude earthquake struck Niigata Prefecture, Japan, the Shinkansen train Ibis 325 was operating at $200 \mathrm{~km} / \mathrm{h}$, and the earthquake directly led to the derailment of train group. Fortunately, there were no casualties [1]. On March 4, 2010, a high-speed train was going through Tainan New City when a 6.7 magnitude earthquake hit Kaohsiung, which caused two wheels to derail. Due to the vast and scattered nature of the earthquake area, as well as variable earthquake frequencies, it is inevitable that HRS may be hit by earthquakes during operation, which shows tremendous significance to research the railway traffic safety under the earthquake. Scholars and engineers have also been conducting research and simulation of high-speed trains operation under seismic events.

Currently, train-track-bridge (TTB) model analysis is maturing [2-4]. These studies based on finite element (FE) modeling have formed a relatively complete theoretical system of the response of TTB system. Xu et al. $[5,6]$ developed a TTB model based on coupling strategies and matrix representations with track irregularity as excitation. 


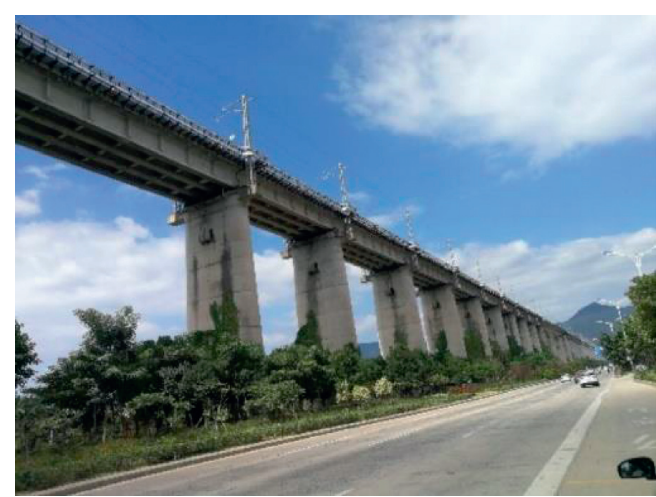

Figure 1: HSR bridge (Xiangtang-Putian Railway line).

Zakeri et al. [7] investigated the sensitivity of different structural parameters and the dynamic response of structural under different moving-load speed.

The establishment and investigation of these TTB models make the original rough model more accurate and reliable and lead to more realistic simulation results. With the development of the TTB theory and model, scholars also began to investigate the operation safety problem under seismic excitation. Yang and $\mathrm{Wu}[8]$ investigated the dynamic stability and derailment of train group under earthquake. Nishimura et al. [9] revealed the relationship of vehicle speed and wheel slide under seismic through comparison between full-scale experiment and model simulation. The research results of Montenegro et al. [10] show that, in the design of high-speed railway simply supported beam bridges, although moderate earthquakes are not the main threat to structural integrity, it is necessary to take them into consideration in the design process due to the risk of rim climbing and derailment. Yu et al. [11] analyzed in depth the bridge response under near-fault earthquake. These researches provide valuable theoretical basis and reference for the seismic design of HSRSSB. Chen and Zhai [12], Liu et al. [13], and Lai et al. [14] analyzed the running safety and comfort of train passing the bridge considering the girder deformation of bridge. The research of Jin et al. [15] indicates that the ignoration of vertical ground motion components may lead to overestimation of the threshold intensity and will severely affect the safety evaluation of HSRSSB under seismic events. Liu et al. [16] calculated the dynamic response limit of track-bridge system considered running safety under earthquake.

However, some conventional TTB models encounter issues such as modeling complexity and low computational efficiency. In some modeling cases, the length of rail, slab, and girder can be kilometers, in accordance with FE theory, the degrees of freedom (DOF) could be significantly large, which leads to huge computational burden, to further optimize the model, Zhai [17] proposed a family of explicit two-step algorithms which are convenient and economical for large-scale dynamic problems, and Zhu et al. [18] proposed a new hybrid solution algorithm combined with strongly coupled method and loosely coupled method and utilized multi-time-step method to enhance the computational efficiency of TTB coupled model. Tanabe et al. [19] proposed an innovative computational method which has the ability to avoid the round-off error during the calculation of the radical dynamic wheel-rail interaction under seismic excitation. These researches above focused on the continuous creation and innovation of algorithms to improve the accuracy, stability, and computational efficiency of TTB system.

In addition to the enhancement of computational efficiency, increasing modeling efficiency and stability is another way for TTB interaction improvement. Yang and Hwang [20] combined the direct stiffness method and mode superposition method to improve the convergence. Zeng et al. [21] divided rail, slab, girder, and piers into different beam elements and coupled them in accordance with energy principle. Zhang et al. [22] discussed the influence of bridge span number and pier heights on the seismic response sensitivity of HSRSSB. The research is based on an innovative equivalent model, which is obtained by attaching springs with equivalent stiffness of adjacent structures to both sides of the target spans [23].

On top of the contributions mentioned above, some researches improved the accuracy and computational efficiency of the TTB model through innovation of wheel-rail interaction [24-26]. Gu et al. [27] proposed a wheel-rail element to simulate the nonlinear vertical wheel-rail relationship. This element regards the wheel-rail displacement as the form of "additional displacement" to simplify the complex wheel-rail coupling relationship. Liu et al. [28] proposed a novel 3D wheel-rail interaction element (WRI) on the platform OPENSEES. This WRI element is capable of being conducted under many nonlinear scenarios such as nonlinear elements, materials, and algorithms. Moreover, the significant applicability also allows the WRI element to be utilized in various finite element models. Xu et al. [29, 30] analyzed the vehicle-track coupled dynamic system based on multi-finite-element coupling method and multi-time-step solution method.

This paper aims to enhance the TTB interaction efficiency from the perspective of the modeling efficiency and proposes an optimized TTB model. The comparison between this new TTB model and conventional model will validate the accuracy of the new model; meanwhile, the efficiency comparison will be discussed as well. Model performance under seismic excitation will be investigated through the case analysis of seven earthquakes samples, and relevant results will be illustrated.

\section{Efficient Model of TTB System}

2.1. Basic Model Theory. In this paper, the whole TTB system is consisted with high-speed train model and simply supported beam bridge system. The model of high-speed train is considered as a mass-spring-damping system; the car-body, bogie, and wheel set are considered as rigid body. According to the principle of energy variation, the dynamic equation of train can be written as

$$
\mathbf{M}_{v} \ddot{X}_{v}+\mathbf{C}_{v} \dot{X}_{v}+\mathbf{K}_{v} \mathbf{X}_{v}=\mathbf{F}_{v},
$$


where $\mathbf{M}_{v}, \mathbf{C}_{v}$, and $\mathbf{K}_{v}$ denote mass, damping, and stiffness matrix of train, respectively; $\mathbf{F}_{v}$ denotes the force vector of train, and it includes wheel-rail contact force, the gravity of the train itself, and earthquake force.

Finite element method is utilized to establish the model of simply supported beam bridge. The simply supported beam bridges are regarded as Bernoulli-Euler beam elements, and the structural damping of track-bridge (TB) system is assumed as Rayleigh damping [31]. The dynamic equation of the TB system is expressed as

$$
\mathbf{M}_{\mathrm{tb}} \ddot{X}_{\mathrm{tb}}+\mathbf{C}_{\mathrm{tb}} \dot{X}_{\mathrm{tb}}+\mathbf{K}_{\mathrm{tb}} \mathbf{X}_{\mathrm{tb}}=\mathbf{F}_{\mathrm{tb}} \text {, }
$$

where $\mathbf{M}_{\mathrm{tb}}, \mathbf{C}_{\mathrm{tb}}$, and $\mathbf{K}_{\mathrm{tb}}$ denote mass, damping, and stiffness matrix of $\mathrm{TB}$ system, respectively; $\mathbf{F}_{\mathrm{tb}}$ denotes the force vector of the TB system, which includes force of wheel-rail contact and earthquake force.

The train and $\mathrm{TB}$ are coupled as a whole system by wheel-rail contact. Only vertical wheel-rail interaction is investigated in this paper. The wheel-rail force is determined by the amount of vertical compression and calculated in accordance with Hertz nonlinear elastic contact theory.

$$
F_{w i}= \begin{cases}\frac{1}{G^{3 / 2}}\left(\left|z_{w i}-\left(z_{x i}+\eta_{i}\right)\right|\right)^{3 / 2}, & z_{w i}-\left(z_{x i}+\eta_{i}\right) \leq 0, \\ 0, & z_{w i}-\left(z_{x i}+\eta_{i}\right)>0,\end{cases}
$$

where $z_{w i}, z_{x i}$ are the vertical displacement of wheel set and rail at the $x$ point, and $\eta_{i}$ is the track irregularity at $x$ point. $G$ is the contact deflection coefficient, for the abrasion type tread:

$$
G=3.86 R^{-0.115} \times 10^{-8}\left(\mathrm{~m} / \mathrm{N}^{2 / 3}\right),
$$

where $R$ is the wheel rolling radius. Linearize the nonlinear stiffness through equation below:

$$
\begin{aligned}
k_{w} & =\frac{3}{2 G} p_{0}^{1 / 3}, \\
F_{w i}^{\prime} & =k_{w}\left(\left|z_{w i}-\left(z_{x i}+\eta_{i}\right)\right|\right),
\end{aligned}
$$

where parameter $p_{0}$ denotes the static load of wheel set.

In consistence with the elastic potential energy conservation principle, the dynamic equation of the coupled train-track-bridge system can be expressed as

$$
\left\{\mathbf{M}_{v} \ddot{X}_{v}+\mathbf{C}_{v} \dot{X}_{v}+\mathbf{K}_{v} \mathbf{X}_{v}=\mathbf{F}_{v}, \mathbf{M}_{\mathrm{tb}} \ddot{X}_{\mathrm{tb}}+\mathbf{C}_{\mathrm{tb}} \dot{X}_{\mathrm{tb}}+\mathbf{K}_{\mathrm{tb}} \mathbf{X}_{\mathrm{tb}}=\mathbf{F}_{\mathrm{tb}} .\right.
$$

2.2. Closed-Loop TTB System Model. Usually, a ground motion lasts for a long time, and the train runs at a fast speed; thus, in conventional TTB seismic simulation, a simply supported bridge model needs a lot of spans to provide enough operation length for analysis of an integrated process of ground motion. For example, under the scenario of $300 \mathrm{~km} / \mathrm{h}$ operation speed and the 15 -second ground motion, the train will run $1250 \mathrm{~m}$. If a $32 \mathrm{~m}$ standard simply supported bridge is adopted, it would need at least over 40 spans. Such a numerous number of spans will occupy a large amount of computer memory and $\mathrm{CPU}$, and the analysis of the whole process of train safety on bridge under earthquake will bring a large amount of calculation. The purpose of this paper is to propose an efficient model to enhance the efficiency of TTB system simulation for simple supported bridge under the premise of accuracy and reliability.

After a train group passes a certain bridge for a certain distance, the dynamic response of the bridge due to trainpass will gradually reduce till it disappears; therefore, the TTB system can form a closed-loop as shown in Figure 2. When the dynamic response of the bridge span that has passed disappears, the train group will reenter the bridge span through the closed-loop model.

The key principle of the closed-loop TTB model is to decrease the size of TB matrices and improve simulation efficiency as much as possible; in order to achieve this, programming language is utilized to create a pseudoelement at the end of the bridge model, as illustrated in Figure 2. The pseudoelement couples the head and end of bridge together so the high-speed train group can operate back to the head of the bridge (Node A) after finishing one loop of total bridge length. In this way, the simplification of model simulation is obvious and significant. For instance, one 40-span bridge can be replaced by 4 cycles of 10-span bridges, which indicates the size of TB matrices can be decreased $75 \%$. However, it is known that the dynamic response of the TB system is a process of gradual convergence. If the span number set in the proposed model is too small, the high-speed train group passes the same span unit before the dynamic response total convergence, which leads to superposition of vibrations; the acceleration, velocity, and displacement of the bridge span will be different from reality; the calculation accuracy of the model will be affected as well. But if the number of bridge span is too large, the meaning of simplification is lost.

2.3. Program Implementation. The closed-loop TB model can be easily established by coupling the head and end of the TB system matrix. Take the rail stiffness matrix $K_{r}$ and the mass matrix $M_{r}$ of the vertical model for example; it is assumed that the rails of each span have $N_{e 0}$ elements, and the rails between adjacent spans are connected by one element. The number of total rail units is $N_{e}$. The left node of the last element (the $N_{e}$ th element) is the last node of the rail model, and the right node of the $N_{e}$ th element is the first node of the rail model belonging to the first span, as shown in Figure 3. By adopting the matrix "check-in rule," the rail elements can be assembled into a closed-loop rail FE matrix as shown in Figure 4. When the track slab is a longitudinally connected slab, the stiffness matrix and mass matrix adopt the same method; for unit plate track slab, the stiffness matrix and mass matrix are consistent with the bridge model. The damping of the TB system is obtained by Rayleigh damping.

In the closed-loop TTB model, train group will circularly operate on the bridge. Take a two-span closed-loop bridge model and a single-section vehicle model as an example. As shown in Figure 5, the first wheel set $W_{1}$ of the train in 


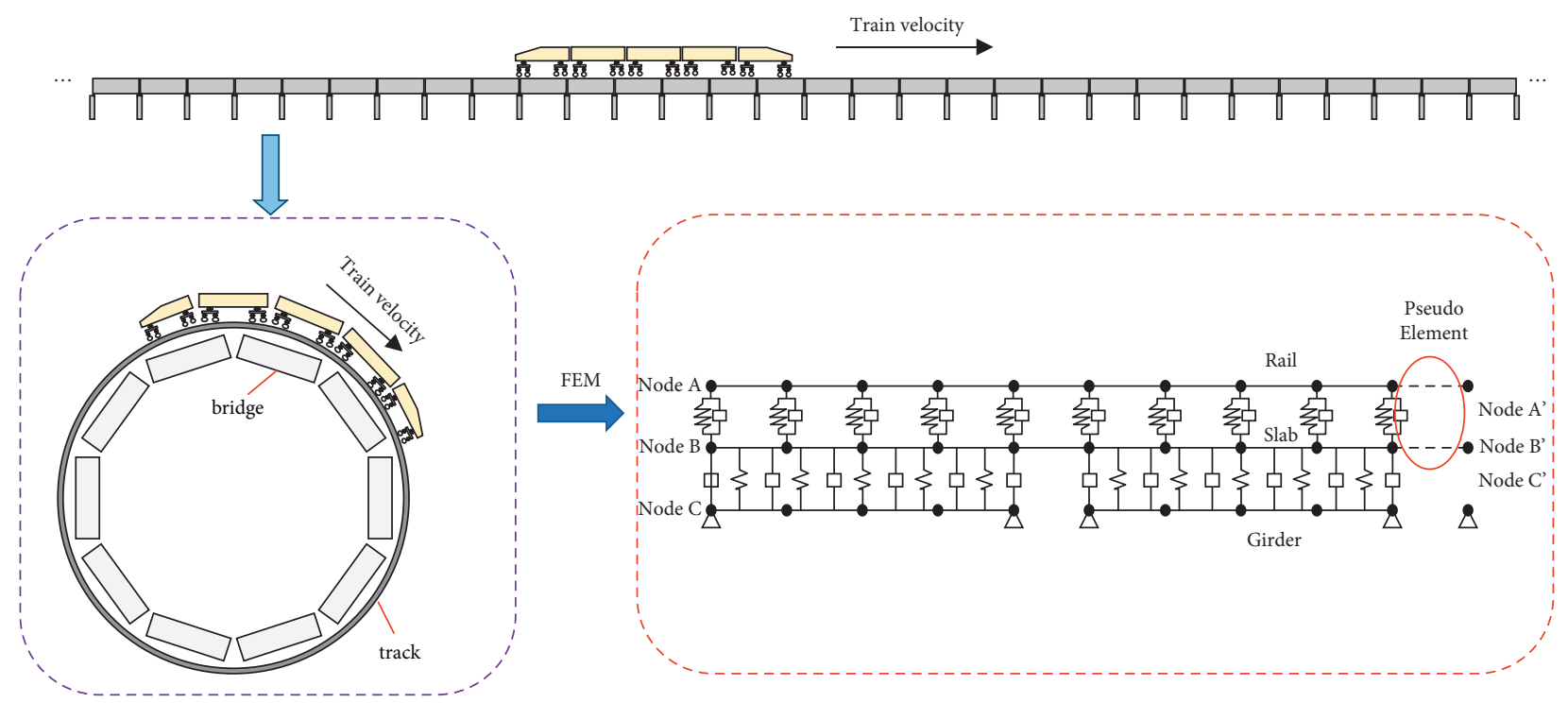

Figure 2: Closed-loop TTB system model.

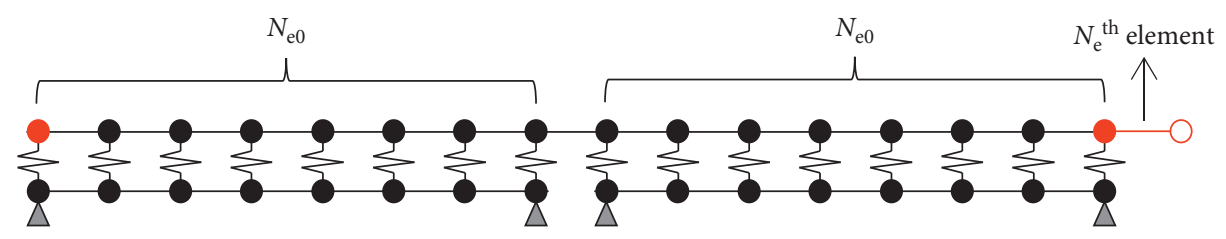

Figure 3: Closed-loop FEM model of rail.

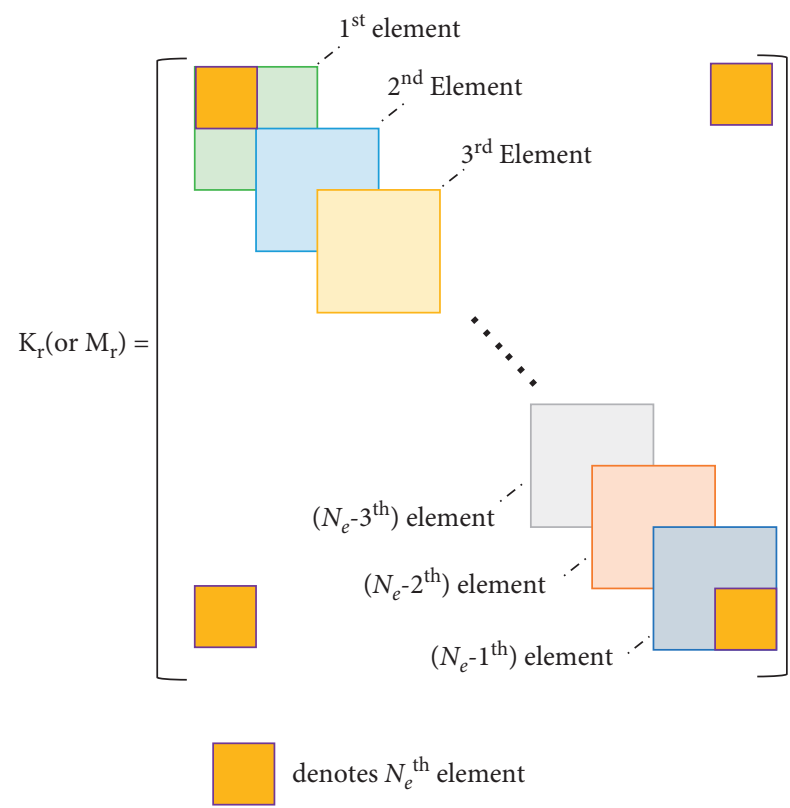

Figure 4: Stiffness assembly of closed-loop rail model.

Figure 5(a) enters the last element. As the train continues to move forward, the wheel set $W_{1}$ returns to the first element as illustrated in Figure 5(b). The track irregularity excitation in the closed-loop TTB system is set as a time domain sample.

\section{Efficient Model Validation}

In the efficient model, ICE-3 train group consisting of 2 bullet trains and 6 trailers is simulated with constant speed, $300 \mathrm{~km} / \mathrm{h}(83.33 \mathrm{~m} / \mathrm{s})$. The parameters of bullet trains and trailers are listed in Table 1.

Based on the prototype of standard $32 \mathrm{~m}$ simply support beam bridge with CRTS II track slab [32] as mentioned in Section 2, the TB system is modeled as a multiple-layer Bernoulli-Euler beam as illustrated in Figure 6. The element length for FE analysis is the spacing of fasteners, $0.64 \mathrm{~m}$, and the bridge approach is set as $200 \mathrm{~m}$ to ensure the carriages and wheel sets stable operation, while rigid subgrade is assumed to make the model more accurate and realistic.

Integral step size of the Newmark- $\beta$ integration method is set as $10^{-4}$ seconds, and the total operation time of the high-speed train is 15 seconds. The parameters of TB system are listed in Table 2.

Closed-loop models with five-span, seven-span, ninespan, and eleven-span are simulated, and the modeling results including vertical displacement at midspan of $1^{\text {st }}$ span are gathered and compared with 30-span simply supported beam bridge model (comparison group). The properties of trains and TB system of all models mentioned above are the same, which are listed in Tables 1 and 2, the head of the 30span bridge is directly connected with bridge approach, and the end of bridge is connected with rigid subgrade, which is different from closed-loop models. 


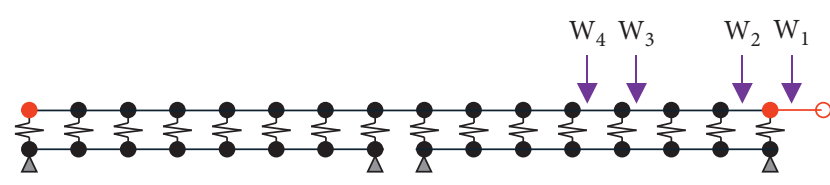

(a)

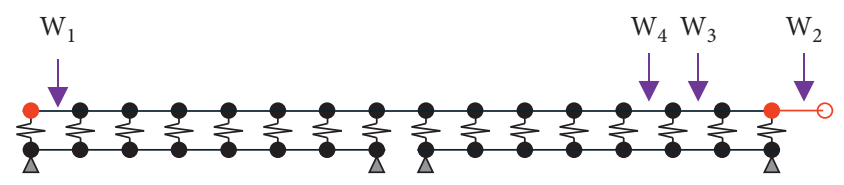

(b)

Figure 5: Closed-loop model of TTB system.

TABle 1: Properties of train group.

\begin{tabular}{|c|c|c|c|c|}
\hline Notation & Item & Unit & Trailer car & Bullet train \\
\hline$m_{c}$ & Mass of car-body & $\mathrm{kg}$ & $4.40 \times 10^{4}$ & $4.80 \times 10^{4}$ \\
\hline$m_{t}$ & Mass of bogie & $\mathrm{kg}$ & $2.40 \times 10^{3}$ & $3.20 \times 10^{3}$ \\
\hline$m_{w}$ & Mass of wheel set & $\mathrm{kg}$ & $2.40 \times 10^{3}$ & $2.40 \times 10^{3}$ \\
\hline$J_{c} w$ & Mass moment of inertia of car-body & $\mathrm{kg} \cdot \mathrm{m}^{2}$ & $2.70 \times 10^{6}$ & $2.70 \times 10^{6}$ \\
\hline$J_{t}$ & Mass moment of inertia of bogie & $\mathrm{kg} \cdot \mathrm{m}^{2}$ & $2.20 \times 10^{3}$ & $7.20 \times 10^{3}$ \\
\hline$k_{1 z}$ & Spring stiffness of the primary suspension & $\mathrm{N} / \mathrm{m}$ & $0.70 \times 10^{6}$ & $1.00 \times 10^{6}$ \\
\hline$k_{2 z}$ & Spring stiffness of the second suspension & $\mathrm{N} / \mathrm{m}$ & $3.00 \times 10^{5}$ & $4.00 \times 10^{5}$ \\
\hline$c_{1 z}$ & Damping coefficient of the primary suspension & $\mathrm{N} \cdot \mathrm{s} / \mathrm{m}$ & $4.00 \times 10^{4}$ & $3.00 \times 10^{4}$ \\
\hline$c_{2 z}$ & Damping coefficient of the second suspension & $\mathrm{N} \cdot \mathrm{s} / \mathrm{m}$ & $5.00 \times 10^{4}$ & $4.00 \times 10^{4}$ \\
\hline$L c$ & Half of longitudinal distance between the centers of front and rear bogies & $\mathrm{m}$ & 8.6875 & $8.6785 \mathrm{~m}$ \\
\hline$L t$ & Half of bogie axle base & $\mathrm{m}$ & $1.25 \mathrm{~m}$ & $1.25 \mathrm{~m}$ \\
\hline$L w$ & Longitudinal distance between the center of bogie and the nearest side of car-body & $\mathrm{m}$ & $4.90 \mathrm{~m}$ & $4.90 \mathrm{~m}$ \\
\hline
\end{tabular}

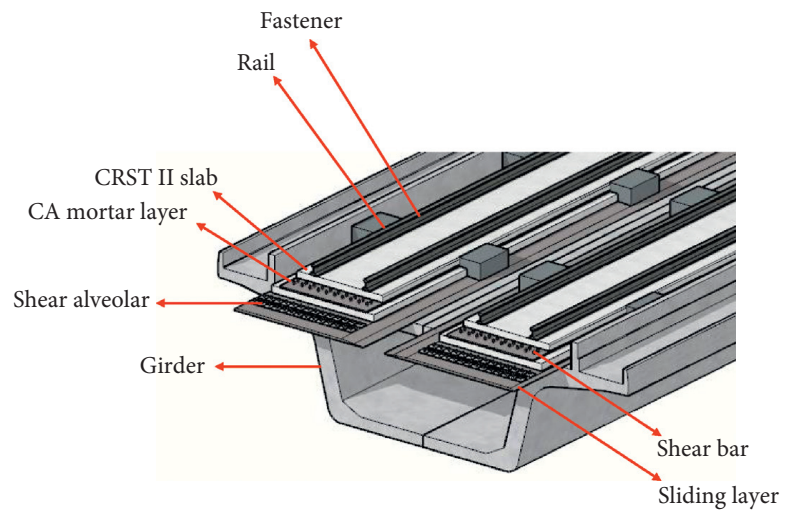

FIgURE 6: CRTS II TB system.

Table 2: Properties of TB system.

\begin{tabular}{lcc}
\hline Notation & Item & Value \\
\hline$E_{r}$ & Young's modulus of rail & $2.06 \times 10^{11} \mathrm{~N} / \mathrm{m}^{2}$ \\
$I_{r}$ & Mass moment of inertia of rail cross section & $2 \times 3.22 \times 10^{-5} \mathrm{~m}^{4}$ \\
$\bar{m}_{r}$ & Mass per unit length of rail & $2 \times 59.66 \mathrm{~kg} / \mathrm{m}$ \\
$E_{s}$ & Young's modulus of slab & $3.6 \times 10^{10} \mathrm{~N} / \mathrm{m}^{2}$ \\
$v_{s}$ & Poisson's ratio of slab & 0.2 \\
$I_{s}$ & Mass moment of inertia of slab cross section & $1.6 \times 10^{-3} \mathrm{~m}^{4}$ \\
$\bar{m}_{s}$ & Mass per unit length of slab & $1.2 \times 10^{3} \mathrm{~kg} / \mathrm{m}^{7}$ \\
$k_{r s}$ & Spring stiffness of fastener & $2 \times 5.0 \times 10^{7} \mathrm{~N} / \mathrm{m}$ \\
$c_{r s}$ & Damping coefficient of fastener & $2 \times 3.625 \times 10^{4} \mathrm{~N} \cdot \mathrm{s} / \mathrm{m}$ \\
$\bar{k}_{s b}$ & Spring stiffness of CA layer per unit length \\
$\bar{c}_{s b}$ & Damping coefficient of CA layer per unit length & $1.5 \times 10^{9} \mathrm{~N} / \mathrm{m}^{2}$ \\
$E_{b}$ & Young's modulus of girder & $8.3 \times 10^{4} \mathrm{~N} \cdot \mathrm{s} / \mathrm{m}^{2}$ \\
\hline
\end{tabular}




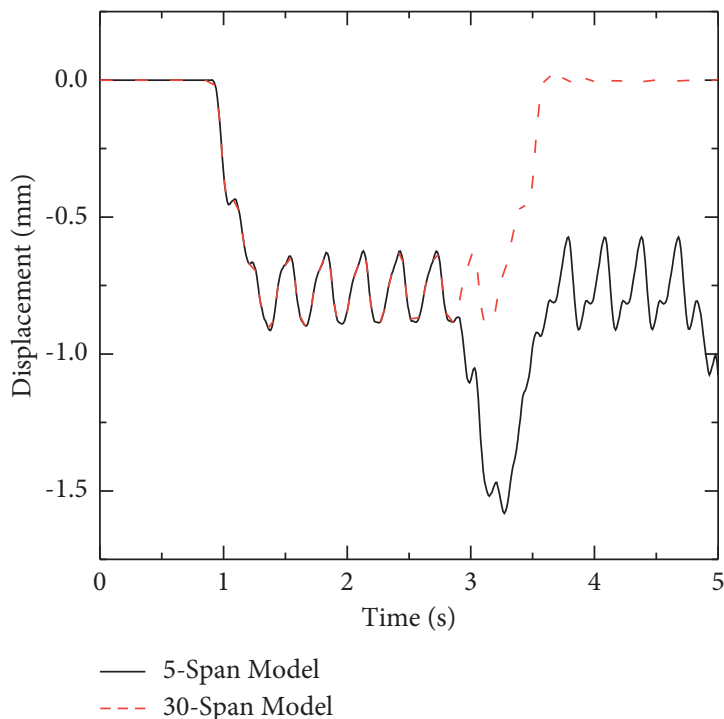

(a)

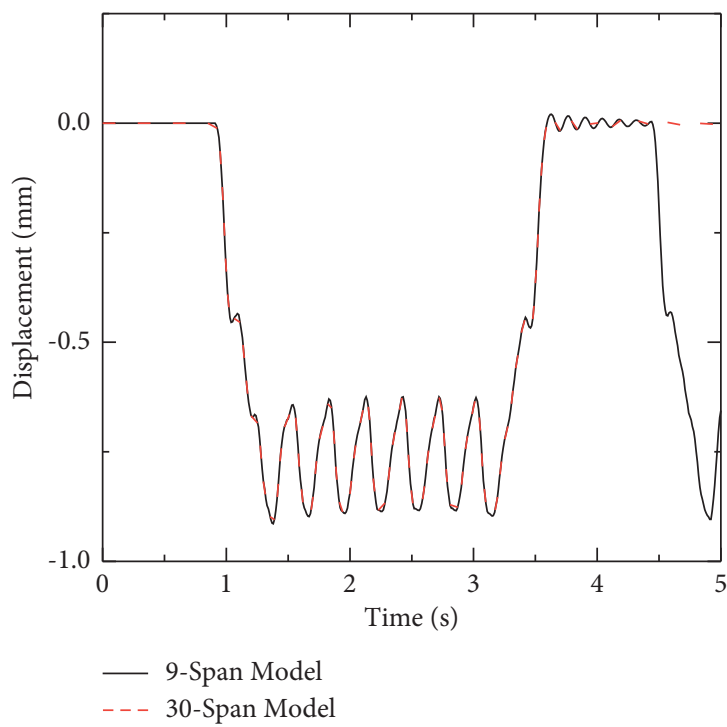

(c)

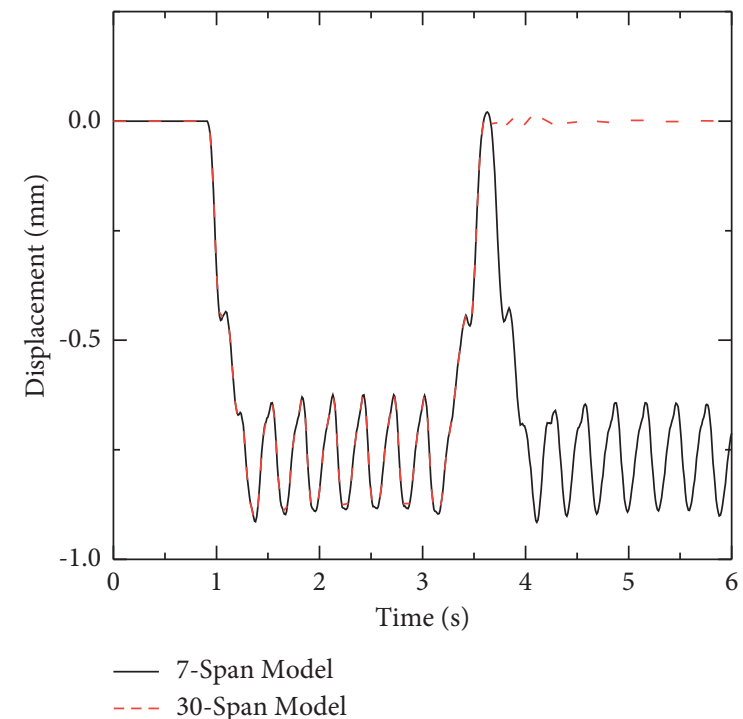

(b)

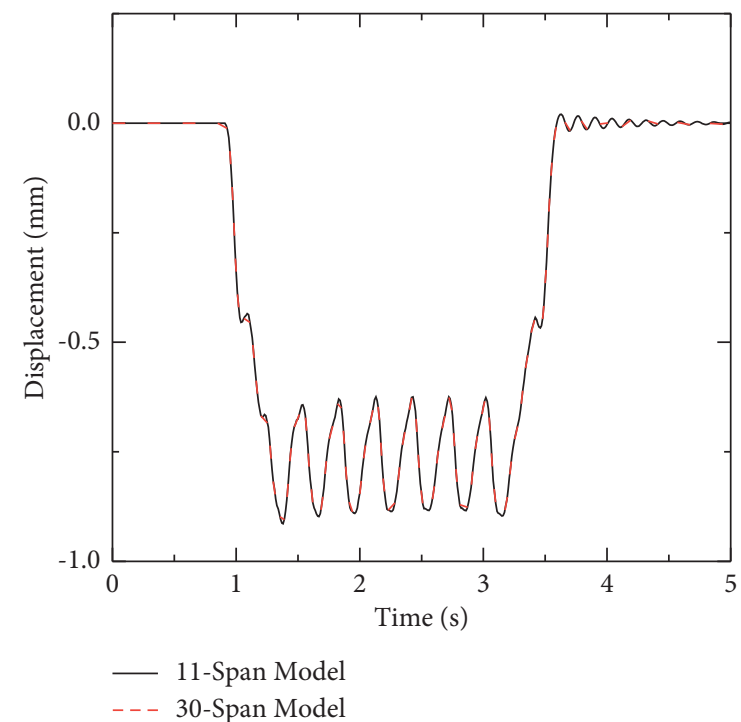

(d)

Figure 7: Comparison of bridge displacement at midspan of 1st span. (a) 5-span efficient model. (b) 7-span efficient model. (c) 9-span efficient model. (d) 11-span efficient model.

TABLE 3: Natural frequency of vibration comparison.

\begin{tabular}{|c|c|c|c|c|c|c|}
\hline Model & Unit & 1st mode & 2nd mode & 3rd mode & 4th mode & 5th mode \\
\hline Nine-span closed-loop model & $\mathrm{Hz}$ & 7.2643 & 7.2643 & 7.2651 & 7.2651 & 7.2664 \\
\hline Thirty-span complete model & $\mathrm{Hz}$ & 7.2642 & 7.2643 & 7.2643 & 7.2644 & 7.2644 \\
\hline Error & $\%$ & 0.00138 & 0 & 0.01101 & 0.00964 & 0.02753 \\
\hline
\end{tabular}

Figure $7(\mathrm{a})$ demonstrates the comparison of bridge displacement at midspan of $1^{\text {st }}$ span between 30-span model and closed-loop model with 5-span; it shows that the time-history-displacements of the two models show significant difference from the sixth peak, and the maximum value of five-span closed-loop model is $1.58 \mathrm{~mm}$, while the value of thirty-span model is only $0.91 \mathrm{~mm}$; the potential reason for the difference is the vibration superposition.

As for comparison of other closed-loop models, the timehistory-displacements are basically consistent with the thirtyspan model as illustrated; however, in Figure 7(b), the timehistory-displacement of the convergence part is covered by the reentry of the train group; to show the complete vibration 


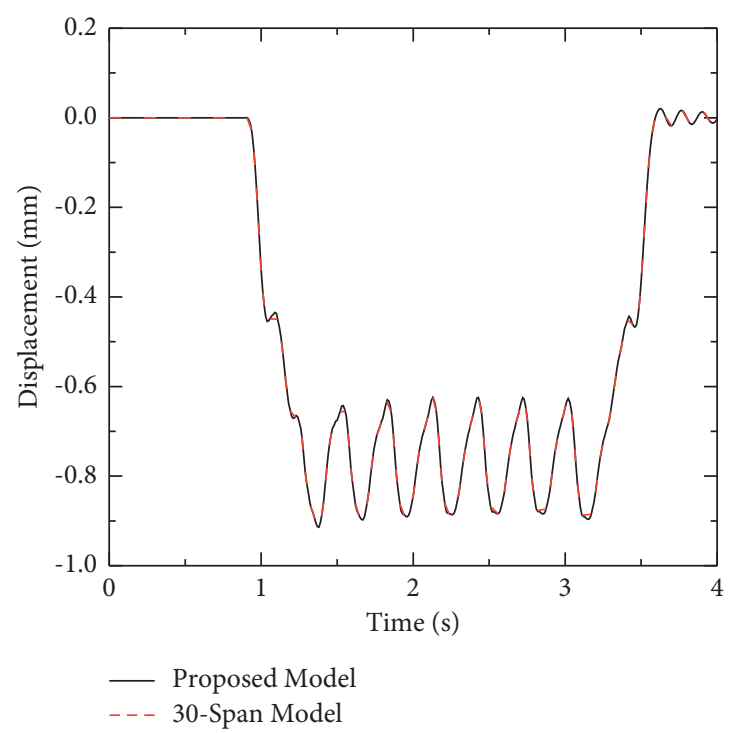

(a)

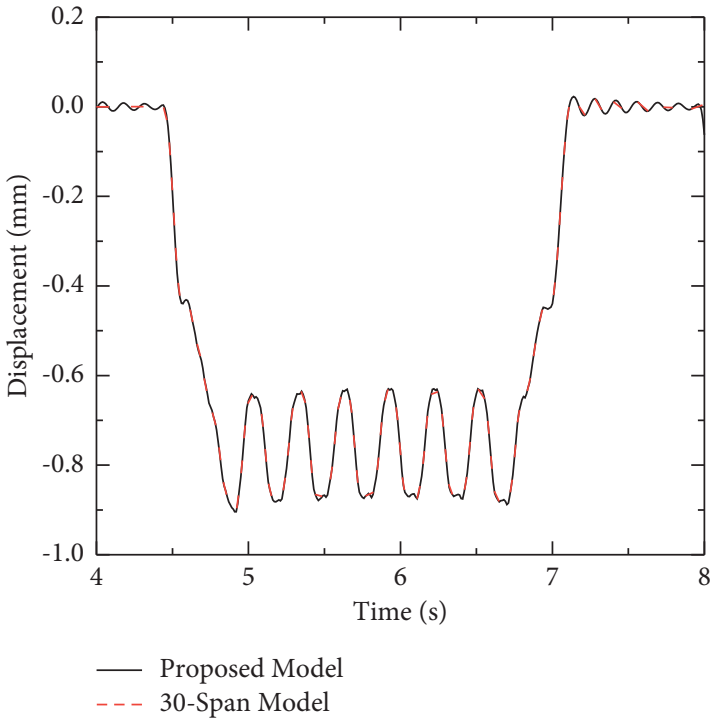

(b)

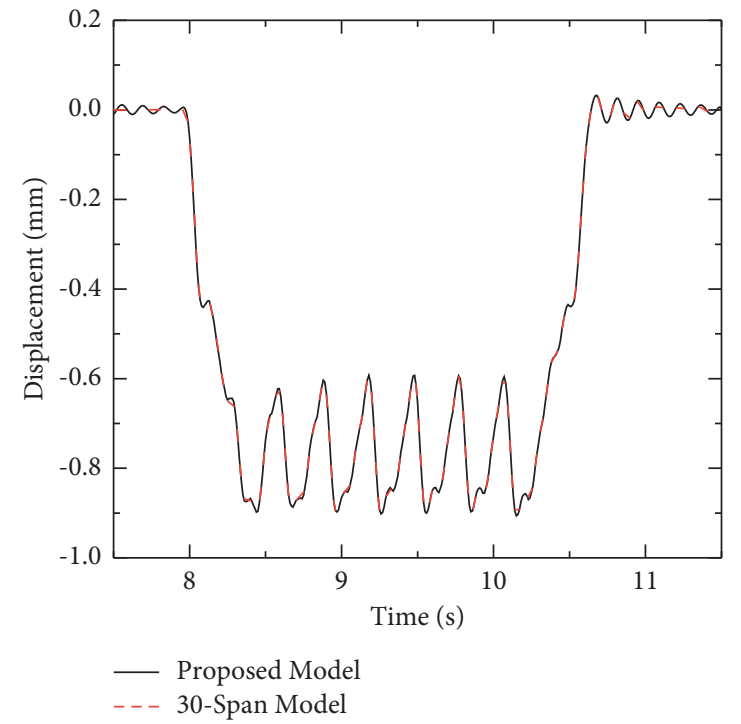

(c)

Figure 8: Responses of bridge displacements at mid span. (a) At the 1st span. (b) At the 10th span. (c) At the 19th span.

process of the bridge, closed-loop models with more cycle spans are necessary. In Figures 7(c) and 7(d), closed-loop models with nine-span and eleven-span can both record the integrated convergence of bridge vibration, but the DOF of eleven-span model is larger than nine-span model; meanwhile, the computational time costs of eleven-span and ninespan model are 390 seconds and 316 seconds. It can be concluded that, under the operation speed at $300 \mathrm{~km} / \mathrm{h}$ $(83.33 \mathrm{~m} / \mathrm{s})$, the nine-span efficient model can guarantee the precision of calculation and achieve the most efficient model analysis.

Besides the operation speed and the span-length of the bridge, other parameters such as the length of the car-body as well as the number of train-groups also affect the span number of the closed-loop model. This paper only analyzes and discusses the above-mentioned working conditions.
In order to validate the nine-span efficient model and measure the accuracy of it, further investigation is conducted. In Table 3, the natural frequency of vibration comparison reveals that the first five modes' frequencies of the two models are similar, which leads to similar responses of the two bridge models under external excitation.

Different from the thirty-span model, the high-speed train of closed-loop model with nine-span returns back to the $1^{\text {st }}$ span instead of leaving the bridge; thus, the $1^{\text {st }}$ span of the closed-loop model can be equivalent to the $1^{\text {st }}, 10^{\text {th }}$, $19^{\text {th }}$, and $(1+9 \times n)$ th spans of the thirty-span model; as a consequence, in this paper, the time-history behaviours of the $1^{\text {st }}$ span, the $10^{\text {th }}$ span, and the $19^{\text {th }}$ span of the thirtyspan model are gathered and compared with the results of the $1^{\text {st }}$ span in efficient model, to evaluate the accuracy of the efficient model. The comparison time-history 
TABle 4: Maximum value of displacement at mid span.

\begin{tabular}{|c|c|c|c|c|}
\hline Model & Unit & 1st span & 10th span & 19th span \\
\hline Nine-span closed-loop model & $\mathrm{mm}$ & 0.895 & 0.904 & 0.906 \\
\hline Thirty-span model & $\mathrm{mm}$ & 0.896 & 0.902 & 0.906 \\
\hline Error & $\%$ & 0.11161 & -0.22173 & 0 \\
\hline
\end{tabular}

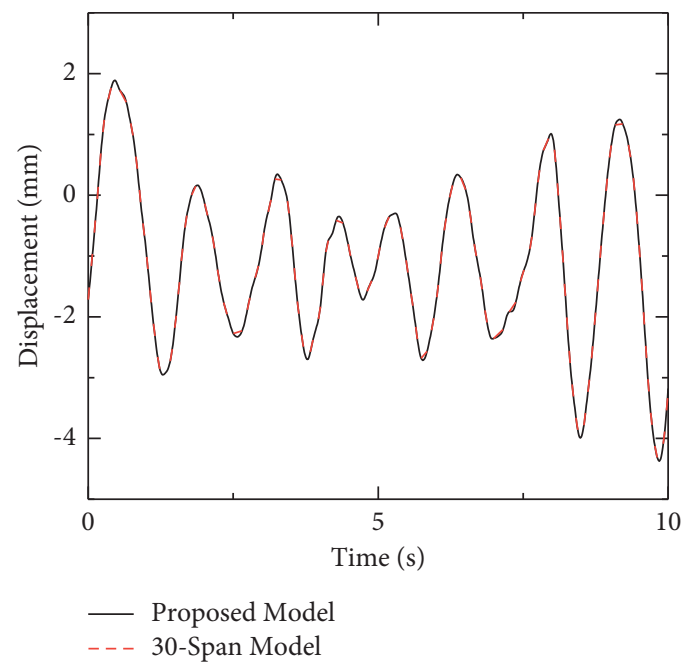

(a)

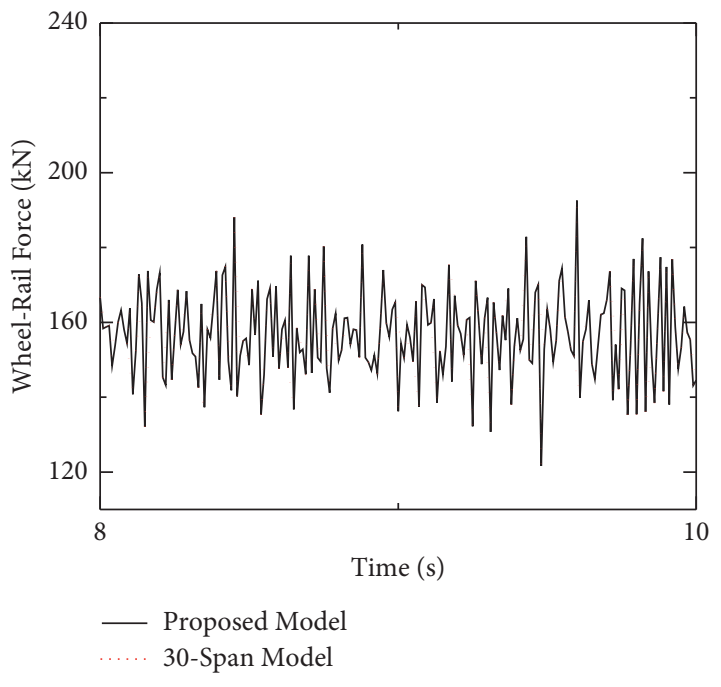

(b)

Figure 9: Vehicle behaviour. (a) Displacement of 1st vehicle. (b) Wheel-rail force of 1st wheel set.

responses of bridge displacements at mid span are shown in Figure 8.

As shown above, the bridge time-history-displacements of these two models both have 7 peaks and 6 troughs and gradually converge to 0 when the high-speed train group passed. The maximum value listed in Table 4 of bridge displacements also indicates that the simulation results of two models are basically consistent and the errors are significantly small. In the time-history-displacement curves shown in Figure 8, differences appeared before the first peak appears; it is because, in the 30-span model, the bridge element does not vibrate before the train goes through, while the bridge element does not have complete convergence before the train goes through again in the closed-loop model.

Time-history wheel-rail force and displacement of vehicle reflect the dynamic response of the vehicle body in the coupling system; the displacement of $1^{\text {st }}$ vehicle and the wheel-rail force of $1^{\text {st }}$ wheel set are collected to validate the vehicle response of closed-loop model, which are shown below. Figure 9(a) captures the $1^{\text {st }}$ vehicle displacement when train group operation is stable. In these two models, the displacements of $1^{\text {st }}$ vehicle oscillate between $1.89 \mathrm{~mm}$ and $-4.32 \mathrm{~mm}$, while in Figure 9(b), the wheel-rail forces of $1^{\text {st }}$ wheel set oscillate between $121.6 \mathrm{kN}$ and $196.1 \mathrm{kN}$, with the oscillation axis of static axle load, $156.8 \mathrm{kN}$. The consistency of these two models in the time-history response of vehicle displacements and wheel-rail forces verifies the accuracy of the efficient model.

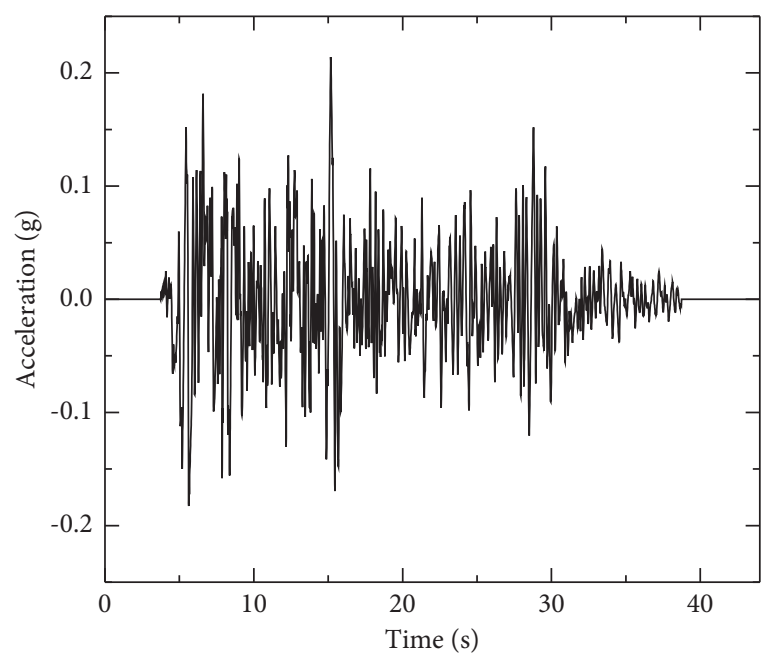

Figure 10: Acceleration of El Centro earthquake.

\section{Seismic Simulation of Efficient Model}

4.1. Model Comparison under Seismic Excitation. In this case, the efficiency and accuracy of 9-span closed-loop model under seismic excitation will be compared with the results obtained by integrated simply supported bridge model. Figure 10 shows the excitation imposed on the TTB system, which is based on El Centro vertical earthquake (referring to PEER Ground Motion Database [33]), the whole earthquake 
TABLE 5: Simulation time cost.

\begin{tabular}{lcccc}
\hline & Unit & $0.1 \mathrm{~g}$ & $0.2 \mathrm{~g}$ & $0.4 \mathrm{~g}$ \\
\hline Nine-span close-loop model & $\mathrm{s}$ & 1333 & 1306 & 1341 \\
115-span complete model & $\mathrm{s}$ & 22084 & 18956 & 22016 \\
\hline
\end{tabular}

${ }^{*}$ The computer hardware configuration is Inter(R) Core (TM) i7-9700 CPU with 16.0 GB RAM.

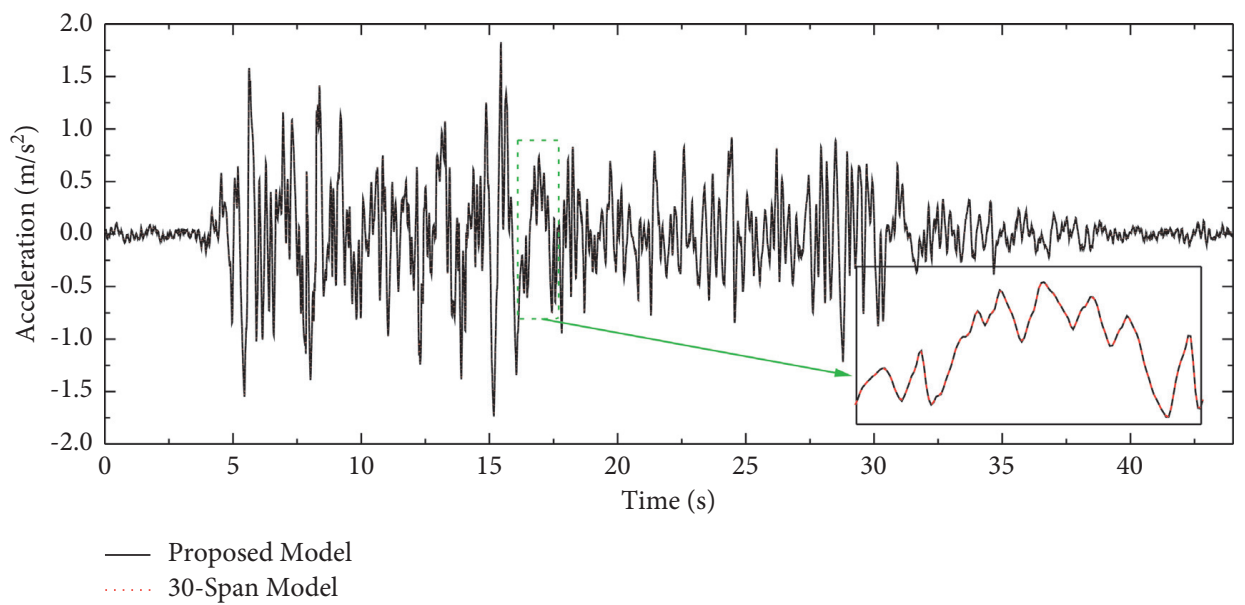

FIgURe 11: Acceleration of 1st car-body (0.4 g).

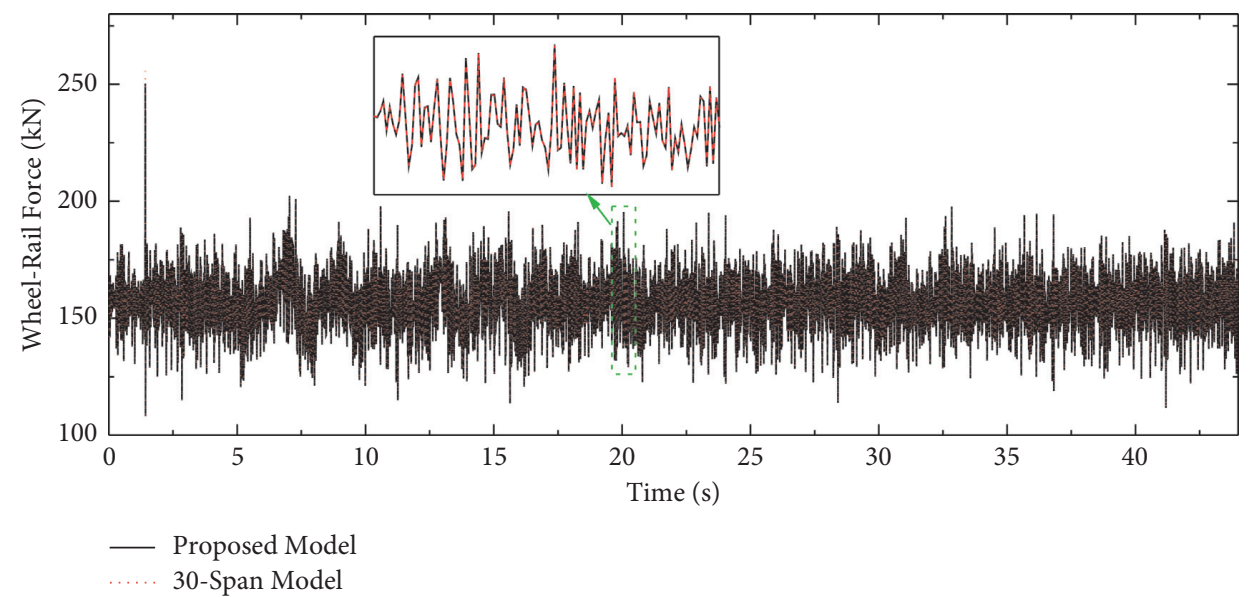

FiguRE 12: Wheel-rail force of 1st wheel set $(0.4 \mathrm{~g})$.

period is 35 seconds, and the acceleration amplitudes of $0.1 \mathrm{~g}, 0.2 \mathrm{~g}$, and $0.4 \mathrm{~g}$ are simulated. As illustrated, the earthquake begins when the last wheel set goes through the bridge approach and contacts TB system. To observe the integrated dynamic response of vehicle and TB system, the total simulation time is 45 seconds. For all results collected and discussed below, the data of the first second are deleted due to the instability of the high-speed train operation.

Under the scenario of $300 \mathrm{~km} / \mathrm{h}(83.33 \mathrm{~m} / \mathrm{s})$ operation speed and 45-second operation time mentioned above, the integrated simply supported bridge model has to be set as a 115-span bridge (35270 DOF) to complete the seismic simulation, while the closed-loop model is only a nine-span bridge model with 2834 DOF, which is only $8 \%$ DOF of the 115-span model. Table 5 lists the simulation time cost of two kinds of model; the efficiency of efficient model is at least 14 times of 115-span model.

Figures 11-13 demonstrate the simulation results comparison between these 2 models under the earthquake acceleration amplitude of $0.4 \mathrm{~g}$. The acceleration of 1 st carbody oscillates between $1.82 \mathrm{~m} / \mathrm{s}^{2}$ and $-1.74 \mathrm{~m} / \mathrm{s}^{2}$, while the error of maximum and minimum acceleration values of 2 models is less than $0.1 \%$. The wheel-rail forces and wheel load reduction ratio results of 1 st wheel set are consistent as well; wheel-rail force oscillates between $114 \mathrm{kN}$ and $202 \mathrm{kN}$. The reason for the mutation value $(250 \mathrm{kN})$ is the unstable 


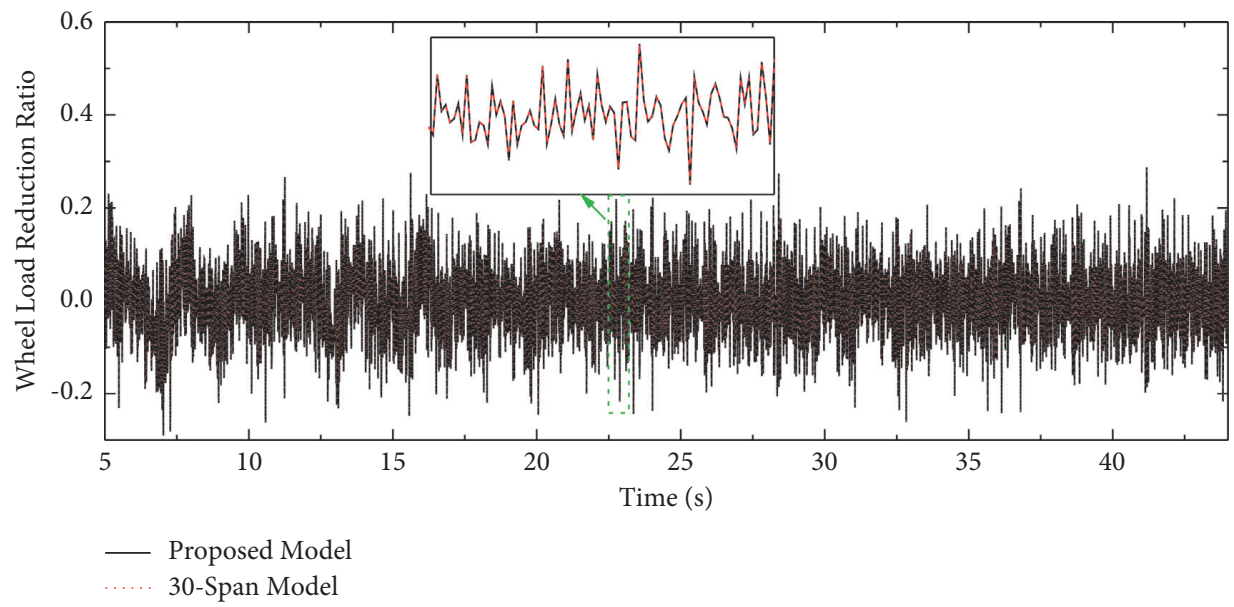

FIgURE 13: Wheel load reduction ratio of 1 st wheel set $(0.4 \mathrm{~g})$.

operation of the wheel set when it contacts with the bridge. The wheel load reduction ratio oscillates between 0.277 and -0.289 . Case 1 validates that the closed-loop model has better computational efficiency compared with conventional model on the premise of accuracy and reliability.

4.2. Response under Vertical Earthquake. Six vertical ground motions are chosen as excitation to observe the response of TTB system under nine-span closed-loop model as listed in Table 6. For all vertical earthquakes, the acceleration amplitudes of $0.1 \mathrm{~g}, 0.2 \mathrm{~g}$, and $0.4 \mathrm{~g}$ are simulated; the results of $1 \mathrm{st}$ car-body acceleration, wheel-rail force, and wheel load reduction ratio of 1 st wheel set are also recorded and illustrated.

Figure 14 demonstrates the system response of 9-span closed-loop model under Kobe vertical earthquake (Figure 15). The time-history acceleration of 1 st car-body is similar to the seismic acceleration, and with the acceleration amplitude increase, the peaks and troughs of time-historyacceleration of car-body scaled accordingly as well. The maximum acceleration of 1 st car-body $(0.1 \mathrm{~g}, 0.2 \mathrm{~g}$, and $0.4 \mathrm{~g})$ is $1.28 \mathrm{~m} / \mathrm{s}^{2}, 2.50 \mathrm{~m} / \mathrm{s}^{2}$, and $4.95 \mathrm{~m} / \mathrm{s}^{2}$, respectively. It is obvious that, with the increase of earthquake acceleration amplitude, the increase of car-body acceleration is linear.

The time-history records of wheel-rail force and wheel load reduction ratio are shown in Figures 14(b) and 14(c), respectively. Wheel-rail force of 1 st wheel set under earthquake acceleration amplitude of $0.1 \mathrm{~g}$ oscillates between $113 \mathrm{kN}$ and $198 \mathrm{kN}$. When earthquake acceleration amplitude increases to $0.2 \mathrm{~g}$, wheel-rail force oscillates between $112 \mathrm{kN}$ and $200 \mathrm{kN}$, and for $0.4 \mathrm{~g}$, wheel-rail force oscillates between $98 \mathrm{kN}$ and $213 \mathrm{kN}$; it is obvious that, with the increase of earthquake acceleration amplitude, the oscillation amplitude of wheel-rail force increases simultaneously, the oscillation amplitude of wheel load reduction ratio increased as well, and the maximum value of wheel load reduction ratio linearly increased from 0.32 to 0.48 .

4.3. Earthquake Comparison and Analysis. In order to investigate the variation trend of car-body acceleration, wheelrail force, and wheel load reduction ratio under different
TABLE 6: Earthquake samples.

\begin{tabular}{lccc}
\hline $\begin{array}{l}\text { Earthquake } \\
\text { name }\end{array}$ & Date & Station name & $\begin{array}{c}\text { Earthquake } \\
\text { magnitude }\end{array}$ \\
\hline Kobe & 1995.01 .16 & Kakogawa & 6.90 \\
Imperial Valley & 1979.10 .15 & USGS & 6.53 \\
Loma Prieta & 1989.10 .18 & CDMG & 6.93 \\
Northridge & 1994.01 .17 & CDMG & 6.69 \\
Tabas Iran & 1978.09 .16 & Dayhook & 7.35 \\
Trinidad & 1980.11 .08 & CDMG & 7.20 \\
\hline
\end{tabular}

${ }^{*}$ All earthquake samples were taken from PEER [33].

acceleration amplitudes, for all earthquake samples mentioned above, seismic excitations with acceleration amplitudes from $0.1 \mathrm{~g}$ to $1.0 \mathrm{~g}$ ( $0.1 \mathrm{~g}$ increase interval) are imposed on the nine-span closed-loop model. The maximum values of parameters mentioned above are collected and illustrated. As shown in Figure 16(a), the increases of maximum acceleration of car-body under these 6 earthquake events are linear. Under the $1.0 \mathrm{~g}$ acceleration amplitudes, the Northridge vertical earthquake leads to maximum car-body acceleration, which is $14.0 \mathrm{~m} / \mathrm{s}^{2}$, and the Trinidad earthquake leads to minimum value, $11.5 \mathrm{~m} / \mathrm{s}^{2}$.

For wheel-rail force, except Imperial Velley vertical earthquake, maximum values of wheel-rail force under other earthquake events linearly increase. $0.7 \mathrm{~g}$ is the slope inflection point of Imperial Velley earthquake, and under the $1.0 \mathrm{~g}$ acceleration amplitudes, the wheel-rail force under Imperial Velley earthquake is at least 3.9 times that of others. Figure 16(c) shows similar situation with wheel-rail force, when acceleration amplitude is larger than $0.6 \mathrm{~g}$, the wheel load reduction ratios of Imperial Velley earthquake reach 1.0, while under other earthquake events, wheel load reduction ratios linearly increase to maximum value of 0.94 . Overall, the dispersion of these three parameters is relatively small under low acceleration amplitude but becomes more and more discrete as the seismic acceleration amplitude increases.

According to relevant Chinese standard [34], the wheel load reduction ratio of train operation should not exceed 0.6 for operation safety considerations. Combined with 


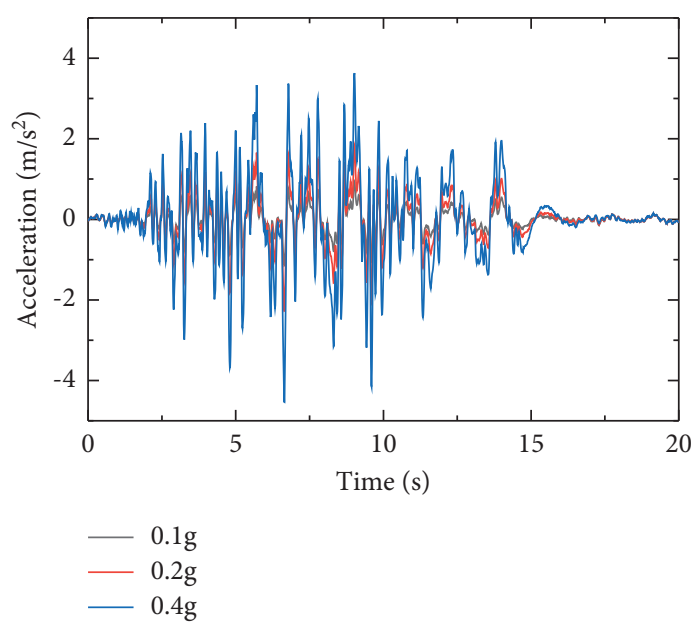

(a)

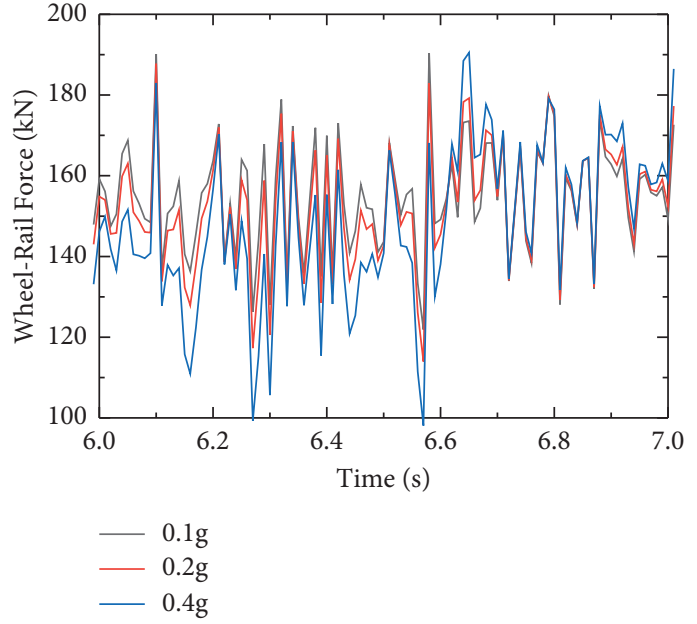

(b)

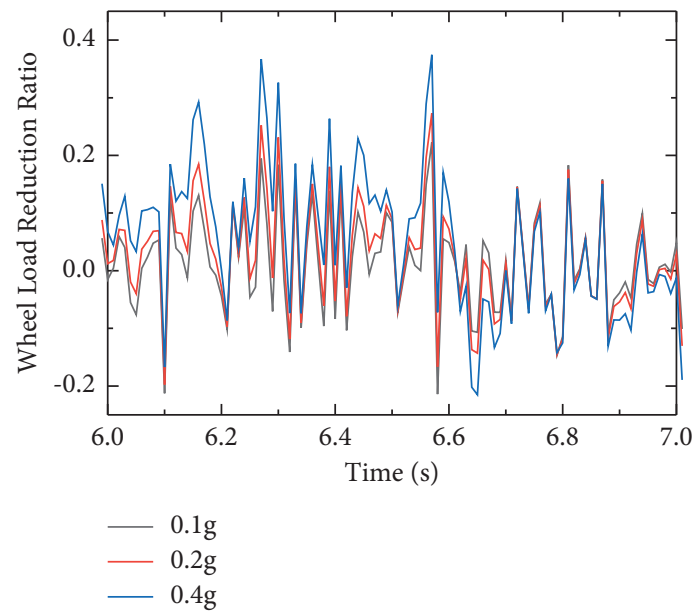

(c)

FIGURE 14: System response under Kobe vertical earthquake. (a) Acceleration of 1st car-body. (b) Wheel-rail force. (c) Wheel load reduction ratio of 1 st wheel set.

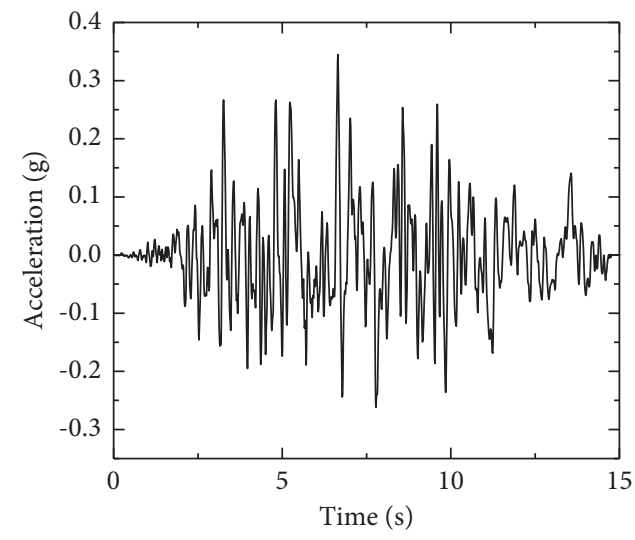

FIgURE 15: Acceleration of Kobe earthquake. 


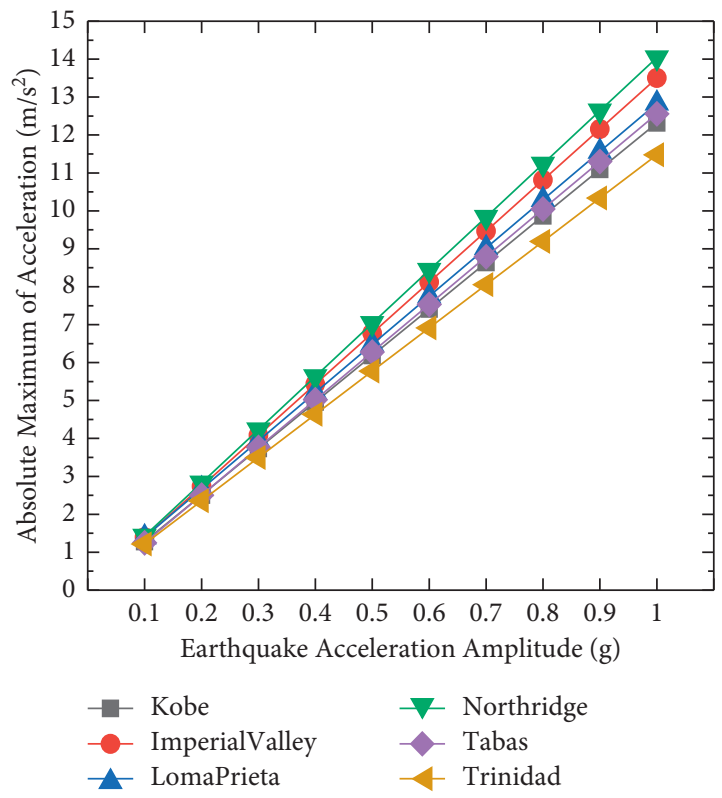

(a)

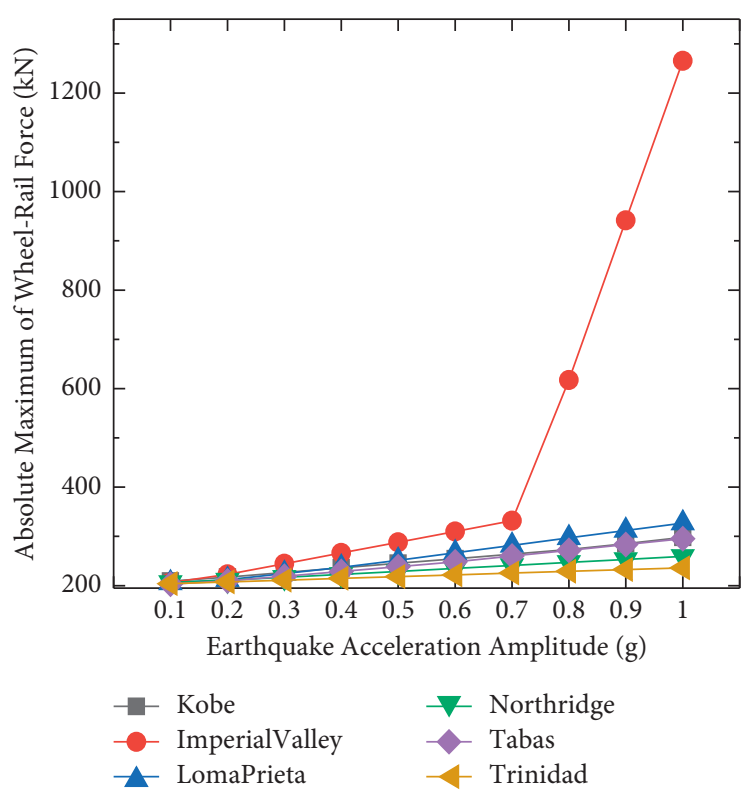

(b)

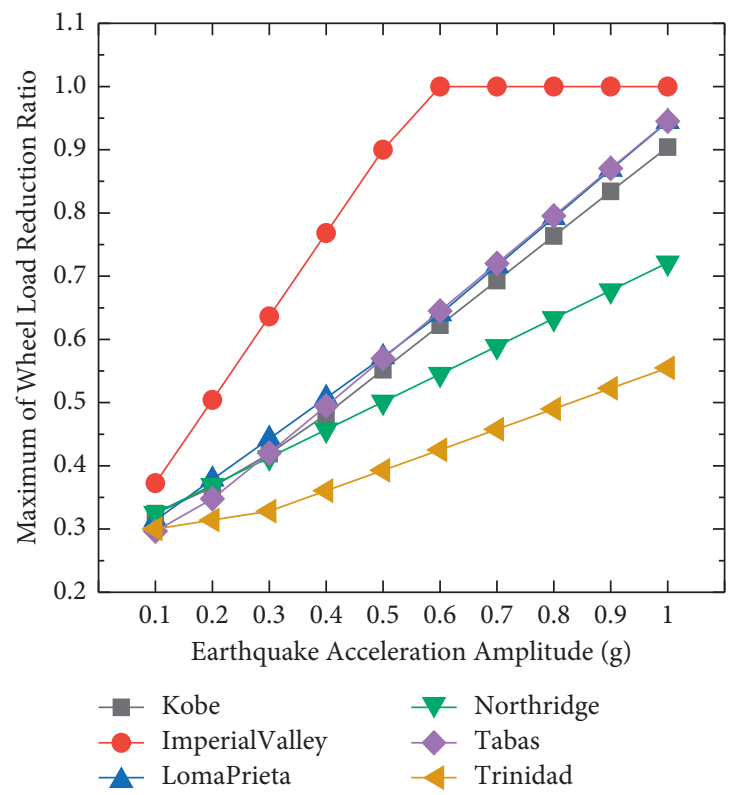

(c)

Figure 16: Maximum value comparison of different vertical earthquake. (a) Acceleration of car-body. (b) Wheel-rail force. (c) Wheel load reduction ratio.

Figure 16(c), under Kobe, Imperial Valley, Loma Prieta, and Tabas Iran earthquake events, acceleration amplitudes exceeding $0.6 \mathrm{~g}$ may lead to derailment due to overweight reduction on one side wheel. The threshold for Northridge is $0.8 \mathrm{~g}$, and for Trinidad earthquake, when acceleration amplitude is larger than $1.0 \mathrm{~g}$, the train operation may be at risk of derailment.

\section{Conclusion}

This paper proposes an efficient model called closed-loop model for TTB system simulation under seismic excitation.
The TB system is modeled as three-layer Bernoulli-Euler beam in accordance with finite element theory, and the simplification of the model is obtained by coupling the head and end of TB system with pseudo-element. ICE-3 highspeed train group containing 2 bullet trains and 6 trailers with linear suspension are modeled as a mass-springdamping system. A comparison between nine-span closedloop model and thirty-span without simplification is set to validate the accuracy of the model and the consistency of maximum displacement of bridge at midspan, acceleration of car-body, and wheel-rail force verifies the reliability of this new efficient model. Simulation under El Centro vertical 
earthquake proves that the closed-loop model has calculation accuracy under seismic excitation. Investigation and analysis under six earthquake events reveal that, under different acceleration amplitude of different earthquakes, the variation of car-body acceleration, wheel-rail force, and wheel load reduction ratio are basically linear. All investigation could be concluded as below:

(1) The closed-loop model is reliable and accurate, regardless of whether the seismic excitation is simulated. When compared with conventional model, the errors of maximum value bridge displacement at midspan are less than $0.2 \%$; the time-history records of carbody acceleration and wheel-rail force are consistent as well. However, in this paper only one working condition is discussed; if the model parameters such as train operation speed change, the span number of closed-loop model should be adjusted as well.

(2) The closed-loop model has high computational efficiency. For instance, under the scenario of $45 \mathrm{~s}$ operation time, the total DOF of efficient model is only $8 \%$ that of conventional model. Meanwhile, the computational time cost is one-fourteenth that of conventional model.

(3) The acceleration amplitude directly affects the response of train group. Take the Kobe vertical earthquake for example; with the increase of earthquake acceleration amplitude, the oscillation amplitudes of time-history 1st car-body acceleration, wheel-rail force of 1st wheel set, and wheel load reduction ratio of 1 st wheel set changed simultaneously.

(4) As for different earthquake samples, with the increase of earthquake acceleration amplitude, the maximum values of train operating indicators mentioned above linearly increase simultaneously. When the earthquake acceleration amplitude exceeds $0.7 \mathrm{~g}$, the maximum wheel-rail force under Imperial Velley earthquake increases with a significantly larger slope, and the wheel load reduction ratio reaches 1.0. According to relevant Chinese standard [34], except the Trinidad earthquake, with other earthquake events with larger than $0.8 \mathrm{~g}$ acceleration amplitude, the train operation is at the risk of derailment.

(5) Though the closed-loop model proposed in this article is mainly focused on vertical TTB interaction response, it provides new modeling ideas for the TTB coupling system and puts forward relevant conclusions for vertical seismic as well; with reference to the closed-loop modeling theory of this article, the research on the model aimed at longitudinal and transverse direction seismic is also ongoing.

\section{Data Availability}

The data used to support the findings of this study are included within the article.

\section{Conflicts of Interest}

The authors declare that they have no conflicts of interest.

\section{Acknowledgments}

The work described in this paper was supported by grants from the National Natural Science Foundation of China (Grant nos. U1934207, 51778630, and 11972379) and Key R\&D Program of Hunan Province (Grant no. 2020SK2060).

\section{References}

[1] M. Ogura, "The Niigata Chuetsu earthquake-railway response and reconstruction," Japanese Railway Transportation Review, vol. 43, pp. 46-63, 2006.

[2] X. Liu, L. Jiang, Z. Lai, P. Xiang, and Y. Chen, "Sensitivity and dynamic analysis of train-bridge coupled system with multiple random factors," Engineering Structures, vol. 221, Article ID $111083,2020$.

[3] L. Xu and W. Zhai, "A new model for temporal-spatial stochastic analysis of vehicle-track coupled systems," Vehicle System Dynamics, vol. 55, no. 3, pp. 427-448, 2017.

[4] X. Liu, P. Xiang, L. Jiang, Z. Lai, T. Zhou, and Y. Chen, "Stochastic analysis of train-bridge system using the karhunen-loéve expansion and the point estimate method," International Journal of Structural Stability and Dynamics, vol. 20, no. 2, Article ID 2050025, 2020.

[5] L. Xu, Z. Chen, and W. Zhai, "An advanced vehicle-slab track interaction model considering rail random irregularities," Journal of Vibration and Control, vol. 24, no. 19, pp. 45924603, 2018.

[6] L. Xu and W. Zhai, "A three-dimensional dynamic model for train-track interactions," Applied Mathematical Modelling, vol. 76, pp. 443-465, 2019.

[7] J. A. Zakeri, M. Shadfar, and M. M. Feizi, "Sensitivity analysis of bridge-track-train system to parameters of railway," Latin American Journal of Solids and Structures, vol. 11, no. 4, pp. 598-612, 2014.

[8] Y.-B. Yang and Y.-S. Wu, "Dynamic stability of trains moving over bridges shaken by earthquakes," Journal of Sound and Vibration, vol. 258, no. 1, pp. 65-94, 2002.

[9] K. Nishimura, Y. Terumichi, T. Morimura, M. Adachi, Y. Morishita, and M. Miwa, "Using full scale experiments to verify a simulation used to analyze the safety of rail vehicles during large earthquakes," Journal of Computational and Nonlinear Dynamics, vol. 10, no. 3, Article ID 031013, 2015.

[10] P. A. Montenegro, R. Calçada, N. Vila Pouca, and M. Tanabe, "Running safety assessment of trains moving over bridges subjected to moderate earthquakes: running safety of trains moving over bridges subjected to earthquakes," Earthquake Engineering \& Structural Dynamics, vol. 45, no. 3, pp. 483504, 2016.

[11] J. Yu, L. Jiang, W. Zhou, X. Liu, Z. Lai, and Y. Feng, "Study on the dynamic response correction factor of a coupled highspeed train-track-bridge system under near-fault earthquakes," Mechanics Based Design of Structures and Machines, 2020.

[12] Z. Chen and W. Zhai, "Theoretical method of determining pier settlement limit value for China's high-speed railway bridges considering complete factors," Engineering Structures, vol. 209, Article ID 109998, 2020.

[13] X. Liu, L. Jiang, P. Xiang, L. Jiang, and Z. Lai, "Safety and comfort assessment of a train passing over an earthquake- 
damaged bridge based on a probability model," Structure and Infrastructure Engineering, pp. 1-12, 2021.

[14] Z. Lai, L. Jiang, W. Zhou et al., "Lateral girder displacement effect on the safety and comfortability of the high-speed rail train operation," Vehicle System Dynamics, pp. 1-25, 2021.

[15] Z. Jin, S. Pei, X. Li, H. Liu, and S. Qiang, "Effect of vertical ground motion on earthquake-induced derailment of railway vehicles over simply-supported bridges," Journal of Sound and Vibration, vol. 383, pp. 277-294, 2016.

[16] X. Liu, L.-z. Jiang, P. Xiang, Z.-p. Lai, Y.-1. Feng, and S.-s. Cao, "Dynamic response limit of high-speed railway bridge under earthquake considering running safety performance of train," Journal of Central South University, vol. 28, no. 3, pp. 968-980, 2021.

[17] W.-M. Zhai, "Two simple fast integration methods for largescale dynamic problems in engineering," International Journal for Numerical Methods in Engineering, vol. 39, no. 24, pp. 4199-4214, 1996.

[18] Z. Zhu, W. Gong, L. Wang, I. E. Harik, and Y. Bai, "A hybrid solution for studying vibrations of coupled train-track-bridge system," Advances in Structural Engineering, vol. 20, no. 11, pp. 1699-1711, 2017.

[19] M. Tanabe, M. Sogabe, H. Wakui, N. Matsumoto, and Y. Tanabe, "Exact time integration for dynamic interaction of high-speed train and railway structure including derailment during an earthquake," Journal of Computational and Nonlinear Dynamics, vol. 11, no. 3, Article ID 031004, 2016.

[20] S. C. Yang and S. H. Hwang, "Train-track-bridge interaction by coupling direct stiffness method and mode superposition method," Journal of Bridge Engineering, vol. 21, no. 10, Article ID 04016058, 2016.

[21] Z.-P. Zeng, F.-S. Liu, P. Lou, Y.-G. Zhao, and L.-M. Peng, "Formulation of three-dimensional equations of motion for train-slab track-bridge interaction system and its application to random vibration analysis," Applied Mathematical Modelling, vol. 40, no. 11-12, pp. 5891-5929, 2016.

[22] Y. Zhang, L. Jiang, W. Zhou, Y. Feng, X. Liu, and Z. Lai, "Critical coupling span number in high-speed railway simply supported beam bridge," Smart Structures and Systems, vol. 28, pp. 13-28, 2021.

[23] Y. Zhang, L. Jiang, W. Zhou, Y. Feng, Z. Tan, and X. Chai, "Study of bridge-subgrade longitudinal constraint range for high-speed railway simply-supported beam bridge with CRTSII ballastless track under earthquake excitation," Construction and Building Materials, vol. 241, Article ID 118026, 2020.

[24] Y.-B. Yang and J.-D. Yau, "Vehicle-bridge interaction element for dynamic analysis," Journal of Structural Engineering, vol. 123, no. 11, pp. 1512-1518, 1997.

[25] C. J. Bowe and T. P. Mullarkey, "Wheel-rail contact elements incorporating irregularities," Advances in Engineering Software, vol. 36, no. 11-12, pp. 827-837, 2005.

[26] Y. Ma, V. L. Markine, A. A. Mashal, and M. Ren, "Improving the performance of finite element simulations on the wheelrail interaction by using a coupling strategy," Proceedings of the Institution of Mechanical Engineers, Part F: Journal of Rail and Rapid Transit, vol. 232, no. 6, pp. 1741-1757, 2018.

[27] Q. Gu, Y. Liu, W. Guo, W. Li, Z. Yu, and L. Jiang, "A practical wheel-rail interaction element for modeling vehicle-trackbridge systems," International Journal of Structural Stability and Dynamics, vol. 19, no. 2, Article ID 1950011, 2019.

[28] Y. Liu, P. A. Montenegro, Q. Gu, W. Guo, R. Calçada, and J. Pombo, "A practical three-dimensional wheel-rail interaction element for dynamic response analysis of vehicle-track systems," Computers \& Structures, vol. 254, Article ID 106581, 2021.

[29] L. Xu and X. Liu, "Matrix coupled model for the vehicle-track interaction analysis featured to the railway crossing," $\mathrm{Me}$ chanical Systems and Signal Processing, vol. 152, Article ID 107485, 2021.

[30] L. Xu, Z. Li, Y. Zhao, Z. Yu, and K. Wang, "Modelling of vehicle-track related dynamics: a development of multi-finiteelement coupling method and multi-time-step solution method," Vehicle System Dynamics, pp. 1-28, 2020.

[31] L. Jiang, X. Liu, P. Xiang, and W. Zhou, "Train-bridge system dynamics analysis with uncertain parameters based on new point estimate method," Engineering Structures, vol. 199, Article ID 109454, 2019.

[32] Z. Lai, L. Jiang, X. Liu, Y. Zhang, and W. Zhou, "Analytical investigation on the geometry of longitudinal continuous track in high-speed rail corresponding to lateral bridge deformation," Construction and Building Materials, vol. 268, Article ID 121064, 2021.

[33] "PEER ground motion database," 2014, https://ngawest2. berkeley.edu/site.

[34] GB 5599-85, Railway Vehicles-Specification for Evaluation the Dynamic Performance and Accreditation Test, 1985. 